\title{
ANALISA PERBANDINGAN STORE IMAGE KONSUMEN ANTARA HYPERMARKET TOKO INDEPENDEN DAN HYPERMARKET DI PUSAT PERBELANJAAN
}

\author{
Edwin Japarianto \\ Program Manajemen Pemasaran, Universitas Kristen Petra \\ Jl. Siwalankerto 121-131, Surabaya \\ E-mail: edwinj@peter.petra.ac.id
}

\begin{abstract}
Abstrak: Penelitian ini dilakukan untuk menganalisis perbandingan citra toko antara Hypermarket di shopping centre dan Hypermarket sebagai toko independen dengan menggunakan metode pemetaan persepsi. Penelitian ini dilakukan dengan mendistribusikan kuesioner kepada 300 responden yang telah berbelanja minimal dua kali di salah satu atau kedua hipermarket tersebut. Alat analisis yang digunakan dalam penelitian ini adalah analisis Multidimensional Scaling hasil ( MDS ) .suatu menunjukkan bahwa setiap hypermarket memiliki karakteristik unik yang membutuhkan strategi manajemen yang berbeda.
\end{abstract}

Kata kunci: Image toko, peta persepsi, hypermarket, pusat perbelanjaan, toko independen

\begin{abstract}
This research was conducted to analyze the comparative of store image between Hypermarket at shopping centre and Hypermarket as independent store using perceptual mapping method. The research was conducted with distributing questioner to 300 respondents who has been shopping at least twice at one or both of those retail hypermarkets. Analysis tool which is used in this study is the analysis of Multidimensional Scaling (MDS).The results showed that each hypermarket has unique characteristics that require different management strategies.
\end{abstract}

Keywords: Store image, perceptual mapping, Hypermarket, shopping centre, independent store.

\section{PENDAHULUAN}

Hypermarketdapat diistilahkan pasar serba ada karena memiliki konsep dagang eceran yang dirancang untuk memuaskan konsumen dengan tiga ciri penting, yaitu harga barang yang bersaing, pilihan produk yang lengkap, dan pemberian pelyanan yang memuaskan.Konsep ini dapat dikombinasi dengan berbagai atribut fisik seperti snack corner, food court, kebijakan garansi harga dan kualitas.

Sebuah ritel memiliki atribut-atribut seperti adanya stock barang, kelengkapan barang, keramahan karyawan, dan sebagainya. Atribut-atribut tersebut dapat dikelompokkan sebagai variabel store image (citra sebuah toko). Store image berhubungan dengan bagaimana persepsi konsumen akan sebuah ritel dan berkaitan dengan positioning sebuah ritel agar dapat membuat persepsi konsumen akan ritel tersebut berbeda dengan ritel kompetitornya, dan membuat konsumen merasa tertarik dan puas dengan atributatibur yang ada pada ritel tersebut. Konsumen akan melihat suatu ritel melalui citranya baik citra itu negatif atau positif.

Dimensi citra toko yang diambil dalam penelitian ini ada lima dimensi yaitu interior, merchandise, service, price range, dan brand name.Dimensi-dimensi inilah yang sangat mempengaruhi sebuah Hypermarket dalam menyajikan store imagenya kepada para konsumennya. Store image dianggap sebagai salah satu asset yang berharga bagi sebuah usaha. Dengan kata lain store image adalah kepribadian sebuah toko dan merupakan sebuah gambaran mengenai apa yang dilihat dan dirasakan oleh konsumen terhadap toko tertentu.

Sebagai sesama ritel hypermarket, baik di dalam pusat perbelanjaan maupun toko independen memiliki unsur persaingan yang dapat dilihat dari lima dimensi yaitu interior, merchandise, service, price range, dan brand nameyang merupakan unsur pertimbangan konsumen dalam memasuki sebuah ritel hypermarket. Maka dari itu penulis ingin melakukan penelitian "Analisa Perbandingan Store Image Konsumen Antara Hypermarket di pusat perbelanjaan dan Hypermart berupa toko independen dengan Menggunakan Metode Peta Persepsi”.

\section{LANDASAN TEORI}

\section{Retailing}

Menurut Levy (2009) adalah "himpunan kegiatan bisnis yang menambahkan nilai ke produk dan jasa yang dijual kepada konsumen untuk penggunaan pribadi atau keluarga" (p.8).

Menurut Dunne, Lusch dan Griffith (2002) adalah "kegiatan akhir dan langkah-langkah yang 
diperlukan untuk menempatkan barang dagangan yang dibuat dimanapun tempatnya, ke tangan konsumen atau untuk menyediakan layanan untuk konsumen" (p.7).

Menurut Berman dan Evans (2010) adalah semua kegiatan yang melibatkan terjadinya penjualan barang atau jasa yang langsung ditujukan kepada konsumen akhir dan dalam penggunaanya hanya untuk keperluan pribadi saja (p.4).

\section{Retail Mix}

Menurut Levy dan Weitz (2009) adalah "alat yang digunakan untuk mengimplementasikan, menangani perkembangan strategi ritel yang dapat digunakan untuk memuaskan kebutuhan dari target market lebih baik dari pada competitor". Retailmix, termasuk variabel pengambilan keputusan oleh retailer untuk memuaskan kebutuhan pelanggan dan mempengaruhi keputusan mereka dalam proses pengambilan keputusan (p.21).

Menurut Dunne, Lusch, dan Griffith (2002) "retailmix adalah kombinasi dari merchandise, assortment, price, promotion, customer service, dan store layout yang memberikan pelayanan terbaik bagi target segmen" (p.53).

\section{Store Image (Citra Toko)}

Setiap toko tentu memiliki imagenya sendirisendiri.Image suatu toko dapat dilihat dari kesan yang didapat konsumen terhadap harga, kelengkapan produk yang ditawarkan, lokasi toko, maupun pelayanan terhadap karyawan.

Menurut Bellenger dan Goldstucker (2002:72), definisi dari store image adalah the customer perception of the store versus competitive store. Artinya adalah bahwa citra toko dapat diartikan sebagai persepsi konsumen terhadap suatu toko dibandingkan dengan toko lain. Citra toko dapat dipandang sebagai suatu hal yang menjadi gambaran dan pikiran konsumen tentang toko, termasuk didalamnya adalah persepsi dan sikap yang diterima melalui panca indera manusia.

Menurut Samli (1998:100), terdapat dimensidimensi utama dalam store image, yaitu:

\section{Merchandise}

Menurut Sullivan dan Adcock (2002:81) ketika konsumen tertarik memasuki sebuah toko ritel, persoalan yang paling penting ialah bagaimana memaksimalkan waktu yang dipakai selama berkunjung dalam toko tersebut.

\section{Service}

Menurut Lovelock dan Wright (2001:5), layanan adalah "An act or performance that creates benefits for customers by bringing about a desires change in or behalf of - the recipient ".Artinya layanan adalah tindakan atau kinerja yang menghasilkan manfaat bagi pelanggan melalui perubahan yang diinginkan.

\section{Convinience}

Definisi umum dari convinience adalah kenyamanan dimana kenyamanan ini merupakan bagian dari atmosphere (suasana). Menurut Berman dan Evans (2003:360), yang dimaksud dengan atmosphere adalah "Physical characteristicof the storethat are used to develop an image and to draw customer."

\section{Physical Facilities}

Yang termasuk fasilitas fisik adalah elevator, lampu, air conditioning, kamar kecil, tata ruang, penempatan jalan dan keleluasaan, carpeting, arsitektur.

\section{Promotion}

MenurutBerman dan Evans (2003:391), yang dimaksud dengan promosi ialah Any communication by retailer that informs, persuade, and/or reminds the target marke.

\section{Persepsi}

Persepsi memiliki kesan yang lebih kuat daripada fakta yang ada sehingga membuat persepsi konsumen terlihat lebih akurat daripada memperlihatkan fakta yang belum tentu dapat diterima oleh konsumen.Persepsi juga dapat diartikan sebagai suatu proses yang dillalui seseorang dalam menyeleksi, mengorganisasi, dan menginterpretasikan informasiinformasi yang didapat dalam rangka membentuk makna tertentu mengenai produk atau merk tertentu. Makna tersebut sering disebut dengan kesan/citral image. Beberapa para ahli manajemen memiliki pendapat mengenai definisi persepsi itu sendiri. (Schiffmann dan Kanuk 2009)

\section{Perceptual Mapping}

Perceptual map menggambarkan posisi dari sebuah produk, line produk merek, atau perusahaan yang berhubungan dengan para pesaingnya.Dapat juga menggambarkan beberapa ukuran, tetapi yang paling umum hanya dua ukuran. Definisi perceptual 
map adalah; "A visualization technique that indicates how customer percieve competing brand in terms of various criteria" (Duncan, 2005, p. 77) Perceptual map adalah sebuah teknik grafik dimana digunakan oleh para marketer yang bertujuan untuk memberikan tampilan gambaran persepsi konsumen atau potensial konsumen. Biasanya memposisikan dari produk, ragam produk, merek atau perusahaan yang ditampilkan berhubung dari persaingan.

\section{METODE PENELITIAN}

\section{Gambaran Populasi dan Sampel}

Populasi adalah gabungan seluruh elemen, yang memiliki serangkaian karakteristik serupa, yang mencakup semesta untuk kepentingan masalah riset pemasaran (Malholtra, 2005, p. 86). Yang menjadi populasi dalam penelitian ini adalah semua orang yang pernah berbelanja di Hypermarket baik dalam pusat perbelanjaan maupun toko independen.

Peneliti akan menyebar kuisioner kepada 300 orang yang pernah berbelanja minimal 2 kali di kedua type hypermarket tersebut dimana setiap hypermarket akan diambil sebanyak 150 responden.

Teknik sampling yang digunakan dalam penelitian ini adalah sampel nonprobabilitas (nonprobability sampling) dengan teknik pengambilan sampelnya adalah teknik quota sampling. Menurut Santoso dan Tjiptono (2001:89), quota sampling merupakan metode memilih sampel yang mempunyai ciri-ciri tertentu dalam jumlah atau kuota yang diinginkan dan untuk memastikan bahwa berbagai sub kelompok atau dari suatu populasi akan terwakilkan pada karakteristik sampel yang relevan dalam jumlah yang diharapkan peneliti. Quota di ambil dengan membagi responden 75 untuk konsumen Hypermart dan 75 untuk konsumen Giant

\section{Definisi Operasional}

a. Interior (X1)

Merupakan karakteristik yang paling menonjol dari tiap type hypermarket

b. Merchandise (X2)

Merupakan persediaan barang dagangan yang terdapat di kedua type hypermarket

c. Excellent Customer Service (X3)

Serangkaian aktivitas dan program yang dilakukan untuk membuat pengalaman belanja konsumen menjadi lebih menarik dan menguntungkan.

d. Price Range (X4)

Berkaitan dengan penetapan harga dari barang yang dijual apakah lebih mahal atau lebih murah dari hypermarket yang lain.

\section{e. Brand name (X5)}

Berkaitan dengan siapakah yang memanajemen toko karena jika manajemennya telah terkenal akan memudahkan menarit minat belanja konsumen.

\section{Multi Dimensional Scaling}

Multi Dimensional Scalling memiliki hubungan dengan pembuatan grafik (map) untuk menggambarkan posisi sebuah objek dengan objek yang lain, berdasarkan kemiripan objek-objek tersebut. Dalam aplikasi penelitian multidimensional scaling (MDS) sering digunakan untuk memetakan persepsi konsumen terhadap suatu objek dengan menggunakan dua dimensi. Dari hasil pemetaan ini akan diperoleh posisi persaingan yang dipersepsikan oleh konsumen. Pasangan objek terdekat dianggap memiliki banyak kemiripan, sedangkan pasangan terjauh memiliki banyak perbedaan.

\section{ANALISA DAN PEMBAHASAN}

\section{Deskripsi Jawaban Responden}

Dalam melakukan analisa univariat akan dilakukan perbandingan awal dari penilaian konsumen terhadap dimensi store imege kedua type hypermarket dengan menggunakan nilai rata rata dan didapat hasil sebagai berikut.

Dari Dimensi penampilan interior merasakan bahwa penampilan dalam toko sama-sama menarik, hanya saja jika berada dalam pusat pebelanjaan memiliki penampilan desain yang lebih menarik hal ini terjadi karen atmosfer pusat perbelanjaan secara umum akan mendukung situsai dalam hypermarket, sedangkan untuk penataan barangnya toko independen lebih menarik hal ini terjadi karena toko independen memiliki kebebasan dalam mengelola toko dan tidak terikat dengan peraturan sperti dalam pusat perbalanjaan. Secara keseluruhan mengenai interiornya, Hypermarketpusat perbelanjaan lebih menarik di banding dalam toko independen karena persaingan ketat dalam sebuah pusat perbelanjaan.

Dari sisi merchandiseproduk yang dimiliki hypermarket dalam pusat perbelanjaan cenderung lebih lengkap dan lebih bervariasi dalam penyajian produk, hal ini terjadi karena persaingan ketat dalam pusat perbelanjaan itu sendiri sehingga perlu untuk melengkapi ragam produk dan kelangkapan agar mampu memenangi persaingan internal, di samping itu karena sewa lokasi yang mahal, sehingga pemanfaatan lokasi dilakukan semaksimal mungkin dengan memampatan dan kelengkapan produk yang di jual. 
Dari sisi excellent service dapat dilihat hampir tidak terdapat perbedaan yang significan dari kedua type Hypermart. Transaksi pembayaran kedua ritel sama-sama mudah, Karyawan kedua ritel juga samasama mampu menguasai produknya, Responden juga setuju bahwa kedua ritel juga memiliki pramuniaga yang ramah. Hal ini terjadi karena keduanya bergerak di bidang usaha yang sama yaitu penjual ritel barang convenience dimana sisi excelent service bukan menjadi perhatian utama dari konsumen

Dari sisi harga dapat dilihat bahwa mengenai harga dalam toko independen biasanya tercerung lebih rendah dari toko dalam pusat perbelanjaan, hal ini terjadi karena mereka tidak terbebani dengan biaya sewa dan service charge yang cukup tinggi.Dalam pemberian diskon, toko independen lebih banyak kebebasan variasi yang mereka tawarkan karena keputusan langsung di tangan manajer tanpa intervensi manajemen pihak pusat perbelanjaan.

\section{Hasil Analisis Dengan Metode Multidimensional Scaling}

a. Hypermarket dalam pusat perbelanjaan

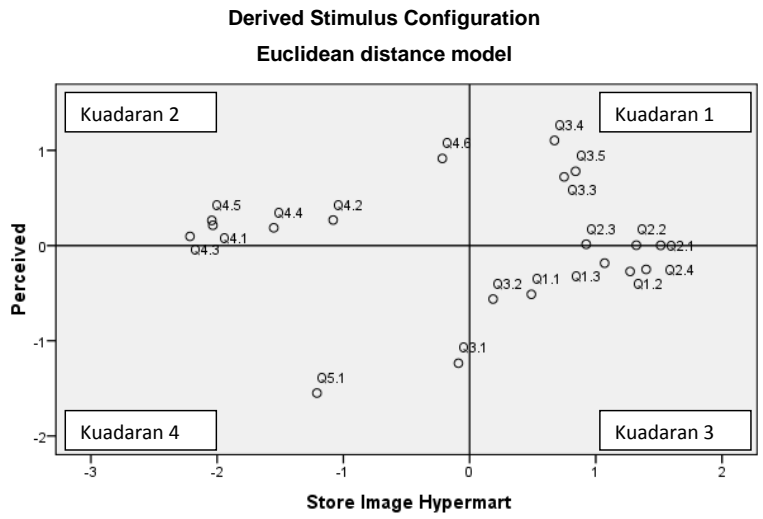

Gambar 1. Peta Persepsi Store Image Hypermarket pusat perbelanjaan

\section{Interior}

Menariknya desain dalam toko (Q1.1) yang berada dalam koordinat 0,49 ; $-0,51$, Penataan rakrak barang yang baik (Q1.2) yang berada dalam koordinat 1,$3 ;-0,27$, dan Lightning yang disajikan sesuai dengan interior toko $(\mathrm{Q} 1.3)$ yang berada dalam koordinat 1,07; - 0,18 berada dalam 1 kuadran tepatnya di kuadran 3 dimana tiap indicatornya saling berpengaruh. Hal ini dibuktikan dengan tiap indikator yang telah disajikan dengan baik tetapi tidak mendapat tanggapan yang baik dari konsumen. Hypermarket dalam pusat perbelanjaan perlu meningkatkan interiornya, karena walaupun apa yang disajikan itu baik tetapi tidak ditanggapi dengan baik bukan berarti konsumen tidak menyukainya karena berdasarkan data kuisioner banyak konsumen yang cukup menyukai interior Hypermarket dalam pusat perbelanjaanhanya saja mereka tidak terlalu memperdulikannya, sehingga bagaimanapun juga tetap harus dijaga kualitas interiornya, sehingga secara tidak mengecewakan konsumen

\section{Merchandise}

Kelengkapan produk (Q2.1) yang berada dalam koordinat 1,5; 0,002, Ketersediaan barang (Q2.2) yang berada dalam koordinat 1,$3 ; 0,004$, dan Pembaharuan variasi produk (Q2.3) yang berada dalam koordinat 0,$92 ; 0,01$ memiliki posisi di kuadran 1 diamana ketiga indikator ini merupakan power bagi Hypermarket dalam pusat perbelanjaankarena merupakan sajian image yang baik dan mendapat tanggapan yang baik pula dari konsumen, perlu mempertahankannya karena inilah keunggulan dari Hypermarket dalam pusat perbelanjaanyang membuat konsumen senang berbelanja di dalamnya, sedangkan untuk indikator Kualitas Barang (Q2.4) yang berada dalam koordinat 1,48; -0,25 memiliki posisi di kuadran 3 dimana kualitas barang cukup baik hanya saja tanggapan konsumen kurang baik, maka dari itu perlu meningkatkannya lebih lagi karena bisa saja hal ini terjadi karena ada beberapa konsumen yang memiliki pengalaman kurang menyenangkan misalnya barang tidak kadaluarsa.

\section{Excellent Customer Service}

Kemudahan dalam pembayaran (Q3.3) yang berada dalam koordinat 0,$75 ; 0,72$, Penguasaan mengenai informasi toko dan barang (Q 3.4) yang berada dalam koordinat 0,$67 ; 1,10$ dan Keramahan pramuniaga (Q3.5) yang berada dalam koordinat 0,$84 ; 0,78$ berada pada posisi kuadran 3 dimana ketiga indikator ini merupakan hal yang dapat membuat image Hypermarket dalam pusat perbelanjaanmenjadi baik dan mendapat tanggapan yang baik pula dari konsumen. Maka dari itu untuk ketiga indikator ini perlu mempertahankannya. Untuk Kecepatan kasir (Q3.1) yang berada dalam koordinat $-0,09 ;-1,24$ berada pada kuadran 4 yang berarti indikator ini dapat membuat image Hypermarket dalam pusat perbelanjaanmenjadi sedikit turun, walaupun penanganan konsumen pada hari Sabtu Minggu atau tanggal muda dengan hari-hari biasa atau tanggal tua tentu berbeda karena terkadang bagian kasir suka meremehkan suasana sepi, tetapi bagaimanapun juga perlu menunjukkan kualitasnya sebagai ritel besar yang sukses sehingga untuk indikator ini sangat 
perlu diperbaiki agar konsumen dapat lebih puas dan tidak merasa rugi atas pengorbanan yang dikeluarkan. Untuk indikator Ketelitian kasir (Q3.2) yang berada pada koordinat 0,$19 ;-0,56$ dengan posisi di kuadran 3 yang berarti bagian kasir telah teliti dalam melaksanakan tugasnya tetapi konsumen tidak menanggapinya dengan baik. Hal ini dapat dikarenakan beberapa kesalahan kecil seperti kesalahan perhitungan dan sebagainya yang jarang terjadi, tetapi apabila sekali terjadi maka dapat membuat Hypermarket dalam puat perbelanaan menjadi sedikit turun dalam mata konsumen. Secara keseluruhan image Excellent Customer Service perlu diperbaiki dan lebih ditingkatkan untuk mencapai kepuasan konsumen.

4. Price Range

Harga terjangkau/murah (Q4.1) yang berada dalam koordinat -2,03; 0,21, Kesesuaian harga dengan kualitas barang (Q4.2) yang berada dalam koordinat $-1,08 ; 0,27$, Ada tidaknya pemberian diskon (Q4.3) yang berada dalam koordinat $-2,22$; 0,10 , Adanya kerja sama dengan bank (Q4.4) yang berada dalam koordinat $-1,55 ; 0,19$, Adanya kupon berhadiah atau voucher (Q4.5)yang berada dalam koordinat $-2,04 ; 0,26$, dan Ada tidaknya pemberian brosur (Q4.6) yang berada dalam koordinat $-0,22 ; 0,91$ memiliki posisi di kuadran 2 yang berarti Hypermarket dalam pusat perbelanjaansendiri tidak terlalu fokus pada keenam indikator ini tapi tanggapan dari konsumen cukup baik. Hal ini dapat disebabkan adanya kepercayaan dan kepuasan tersendiri dari konsumen yang tidak disadari. Seperti soal harga, Hypermarket dalam pusat perbelanjaanmemiliki harga yang lebih baik, tetapi karena kelengkapan, kemudahan pembayaran, dan kenyamanan yang diberikan maka membuat konsumen tidak memikirkan harga.Atau seperti kupon undian. Secara keseluruhan image price range cukup baik akan tetapi juga perlu meningkatkannya karena telah mendapat tanggapan yang baik dari konsumen.

\section{Brand Name}

Pengaruh nama/merk Hypermart dalam menarik minat belanja (Q5.1) yang berada dalam koordinat $-1,2 ;-1,55$ terletak di kuadran 4 yang berarti Hypermarket dalam pusat perbelanjaanitu sendiri tidak terlalu mampu membuat konsumen tertarik untuk berbelanja disana walaupun konsumen juga senang berbelanja di Hypermarket dalam pusat perbelanjaan, maka dari itu perlu memperbaiki dan meningkatkan lagi nama brandnya di pusat perbelanjan dengan memperbaiki semua indika- tor-indikator yang perlu diperbaiki agar pengalaman belanja dapat lebih menyenangkan dan memuaskan konsumen.

b. Hypermarket berupa toko independen

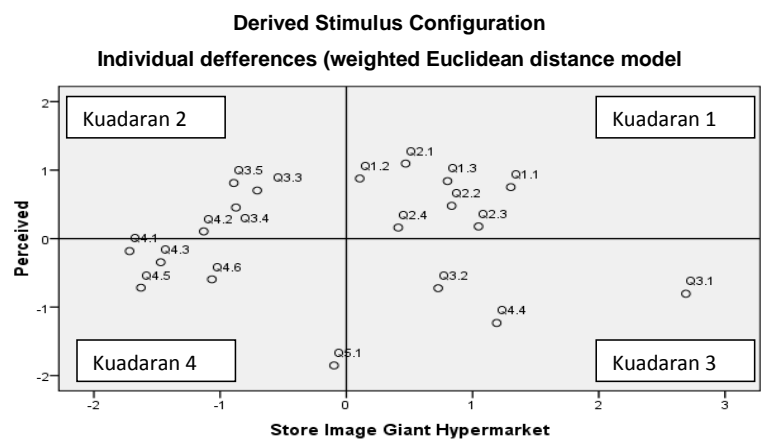

Gambar 2. Peta Persepsi Store Image hypermarket toko independen

\section{Interior}

Menariknya desain dalam toko (Q1.1) yang berada dalam koordinat 1,27; 0,70, Penataan rakrak barang yang baik (Q1.2)yang berada dalam koordinat 0,$14 ; 0,78$, dan Lightning yang disajikan sesuai dengan interior toko (Q1.3) yang berada dalam koordinat 0,$76 ; 0,69$ terdapat di kuadran 1 yang berarti ketiga indikator ini cukup baik disajikan hypermarket toko independen dan mendapat tanggapan yang baik dari konsumen. Maka dari itu perlu mempertahankan ketiga indikator ini.Image interior hypermarket toko independen dapat dikatakan baik sehingga dapat membuat konsumen menjadi betah dalam berbelanja.

\section{Merchandise}

Kelengkapan produk (Q2.1) yang berada dalam koordinat 0,44; 0,95, Ketersediaan barang (Q2.2) yang berada dalam koordinat 0,$79 ; 0,31$, dan Pembaharuan variasi produk (Q2.3) yang berada dalam koordinat 0,96; 0,12, dan Kualitas Barang (Q2.4) yang berada dalam koordinat 0,$42 ; 0,15$ yang terletak di kuadran 1 menandakan bahwa image merchandise hypermarket toko independen cukup baik dimata masyarakat sehingga perlu mempertahankannya sehingga keempat indikator tersebut perlu dijaga kualitasnya agar tidak menurun.

\section{Excellent Customer Service}

Kecepatan kasir (Q3.1) yang berada dalam koordinat 3,07; -0,47, dan Ketelitian kasir (Q3.2) yang berada pada koordinat 0,$76 ;-0,44$ terletak pada kuadran 3 dimana kedua indiaktor ini telah disajikan hypermarket toko independen dengan baik tetapi kurang mendapat tanggapan dari konsumen. 
Hal ini dapat disebabkan karena disaat-saat ramai kasir menjadi sibuk dengan antrian panjang sehingga kecepatan dan ketelitian kasir terkadang menjadi berkurang, atau disaat sepi kasir terlalu meremehkannya sehingga terjadi kesalahan yang jarang terjadi sehingga membuat konsumen menjadi kurang senang, maka dari itu perlu lebih meningkatkan kedua indikator tersebut agar mendapatkan tanggapan yang lebih baik dari konsumen sehingga imagepun dapat menjadi lebih baik. Untuk kemudahan dalam pembayaran (Q3.3) yang berada dalam koordinat $-0,76 ; 0,52$, Penguasaan mengenai informasi toko dan barang (Q 3.4) yang berada dalam koordinat $-0,89 ; 0,37$ dan Keramahan pramuniaga (Q3.5) yang berada dalam koordinat $-0,96 ; 0,77$ terletak pada kuadran 2 dimana ketiga indikator tersebut tidak terlalu dibuat fokus oleh hypermarket toko independen tetapi konsumen cukup baik dalam menanggapinya, maka dari itu perlu mempertahankannya bahkan meningkatkannya sehingga kepuasan akan ketiga indikator tersebut menjadi maksimal. Secara keseluruhan image Excellent Customer Service cukup baik hanya saja perlu penanganan dan peningkatan yang lebih mendalam sehingga dapat meningkatkan image hypermarket toko independen.

4. Price Range

Harga terjangkau/murah (Q4.1) yang berada dalam koordinat $-1,74 ;-0,17$, Ada tidaknya pemberian diskon (Q4.3) yang berada dalam koordinat $-1,49 ;-0,26$, Adanya kupon berhadiah atau voucher $(\mathrm{Q} 4.5)$ yang berada dalam koordinat $-1,64 ;-0,65$, dan Ada tidaknya pemberian brosur (Q4.6) yang berada dalam koordinat -1,08; 0,44 terletak pada kuadran 4 yang berarti keempat indikator tersebut dapat membuat image hypermarket toko independen menurun. Hal ini dapat disebabkan walaupun memang murah, selalu memberikan diskon tetapi apabila hypermarket toko independen sendiri memberikan syarat dan ketentuan yang sedikit berat tentu dapat membuat konsumen menjadi enggan membeli. Maka dari itu mengenai keempat indikator ini hypermarket toko independen harus benar-benar memperhatikannya dan memperbaikinya agar mampu menarik konsumen membeli sesuai dengan buying power mereka.Untuk indicator Kesesuaian harga dengan kualitas barang (Q4.2) yang berada dalam koordinat -1,10; 0,15 terletak di kuadran 2 dimana indikator ini tidak terlalu difokuskan oleh hypermarket toko independen tetapi mendapat tanggapan yang baik oleh konsumen. Maka dari itu perlu lebih memfokuskan pada indikator ini agar kepuasan konsumen terhadap indikator ini tetap terjaga. Untuk indikator Adanya kerja sama dengan bank (Q4.4) yang berada dalam koordinat 1,$20 ;-1,25$ terletak pada kuadran 3 dimana indikator ini telah disajikan hypermarket toko independen dengan baik namun tidak mendapat tanggapan yang baik dari konsumen, hal ini bisa saja karena kerjasama dengan bank-bank masih kurang atau hanya bekerja sama dengan bankbank tertentu yang nasabahnya tidak terlalu umum, sehingga hypermarket toko independen perlu meningkatkannya lebih dalam sehingga konsumen juga dapat menikmati fasilitas banknya..

\section{Brand Name}

Pengaruh nama/merk hypermarket toko independendalam menarik minat belanja (Q5.1) yang berada dalam koordinat $-0,14 ;-1,83$ yang terletak pada kuadran 4 yang berarti konsumen tidak terlalu terbiasa untuk selalu berbelanja di hypermarket toko independen. Maka dari itu perlu memperbaiki seluruh indikator-indikator yang perlu diperbaiki lebih dalam agar konsumen menjadi lebih senang dalam berbelanja di hypermarket toko independen dan tidak berpindah ke ritel yang lain.

\section{KESIMPULAN DAN SARAN}

\section{Simpulan}

Setelah melihat hasil olahan data dengan peta persepsi mengenai perbandingan Store Image antara Hypermarket dala pusat perbelanjaan dengan hypermarket toko independen, terdapat beberapa hal yang dapat disimpulkan.

a. Interior

Interiordalam toko inependen lebih menarik karena kebebasan dalam pengelola outlet tanpa inteervensi pihak lain, sedangkan Hypermarket dalam puat perbelanjaan Interior di gunakan sebagai strategi bersaing.

\section{b. Merchandise}

Image Merchandise Hypermarket dalam pusat perbelanjaan lebih baik karena selain Hypermarket, lokasi dan image pusat perbelanjaan ikut berperan dalam meningkatkan kesan mechandise.

c. Excellent Customer Service

Image Excellent Customer Service antara Giant Hypermarket Maspion Square dengan Hypermart Royal Plaza tidak berbeda jauh, kerana bergarak dalam bidang usaha yang sama.

\section{d. Price Range}

Image Price Range dalam pusat perbelanjaan lebih rendah, karena harga yang di tetapkan harus 
mampu bersaing secara internal dengan toko toko lain dalam pusat perbalanjaan yang sama.

e. Brand Name

Untuk image Brand Name, keduanya tidak terlalu terpengaruh karena pola belanja barang convenience yang cenderung di latar belakangi kebiasaan lokasi belanja.

Setelah mengetahui kesimpulannya, dapat dilihat bahwa positioning yang seharusnya menjadi kelebihan dan kekuatan untuk mendirikan image yang khas dan melekat di pikirankonsumen justru menjadi sebaliknya yaitu kelemahannya. Maka dari itu kelemahan-kelemahan yang dapat menjatuhkan perlu diperbaiki lebih dalam

\section{Saran}

1. Interior

Desain dalam toko akan menjadi lebih menarik apabila mengikuti musimnya. Untuk penataan rak perlu lebih dirapikan dan dibuat jalur lorong yang lebih mudah ditemukan.

2. Excellent Customer Service

Perlu memperkerjakan karyawan bagian kasir yang telah berpengalaman, mampu bekerja secara cepat dan teliti, sabar dan ulet dalam melayani konsumen.

3. Merchandise

Alangkah baiknya apabila barang yang dijual merupakan barang baru yang kadaluarsanya masih sangat lama.

4. Price Range

Perlu untuk bersikap lebih tegas pada slogan dan janji yang diberikan kepada konsumen, perlu sesekali mengadakan kerja sama dengan bank yang umum yang dipakai banyak konsumen.

\section{DAFTAR PUSTAKA}

Barry \& Evans. Joel R. (2003). Retail management: $a$ strategic approach ( $8^{\text {th }}$ ed.). New York: Pearson Prentice Hall

Berman, B., \& Evans J.R. (2010).Retail management: a strategic approach $\left(11^{\text {th }}\right.$ ed.). New Jersey: Pearson Prentice Hall.

Bellenger and Goldstucker.(2002). Retail management strategy.New jersey: Prentice Hall

Duncan, Tom. (2005). Principles of advertising and $\operatorname{imc}\left(2^{\text {nd }} \mathrm{ed}\right)$. McGraw-Hill.

Dunne, Lusch, Griffith. (2002). Retailing $\left(4^{\text {th }}\right.$ ed).New York:south-western, a division of thomson learning.

Levy and Weitz (2009).Retailing management $\left(7^{\text {th }}\right.$ ed.). New York: McGraw Hill.

Lovelock, C.H., Patterson, P.G., \& Walker, R.H. (2001).Service marketing: An Asia-Pacific Perspective ( $2^{\text {nd }}$ ed.). Australia: Prentice Hall

Malhotra, N. (2005). Riset penelitan: pendekatan terapan. (Edisi Keempat) Jakarta: PT. Indeks Kelompok Gramedia

Samli, A. Coskun, J. Patrick Kelly, dan H. Keith Hunt. (1998). Improving the retail performance by contrasting managementand customerperceived store images: adiagnostic tool for corrective action. New Jersey: Prentice Hall

Santoso, Singgih dan Tjiptono, fandy.(2001). Riset pemasaran konsep dan aplikasi.Bandung: Alfa Beta

Schiffman LG, LL Kanuk. (1997). Consumer behavior $6^{\text {th }}$ editions. Upper Saddle River, New Jersey, Prentice-Hall, Inc.

Sullivan, Malcom and adcock, Dennis. (2002). Retail marketing ( $1^{\text {st }}$ ed.). Derby: Saxon Graphics Ltd. 